Referências

1. Silva RA, Jansen K, Souza LD, Moraes IG, Tomasi E, Silva Gdel G, Dias Mde $S$, Pinheiro RT. Depression during pregnancy in the Brazilian public health care system. Rev Bras Psiq. 2010;32(2):139-44.

2. Faisal-Cury A, Menezes P, Araya R, Zugaib M. Common mental disorders during pregnancy: prevalence and associated factors among low-income women in São Paulo, Brazil. Arch Womens Ment Health. 2009;12(5):335-43.

\section{Resposta à carta de Faisal-Cury et al. "Depressão durante a gravidez no sistema público de saúde brasileiro"}

\section{Reply to Faisal-Cury et al.'s letter "Depression during pregnancy in the Brazilian public health care system"}

Caros Editores,

É uma satisfação para a equipe de pesquisa do Programa de PósGraduação em Saúde e Comportamento da Universidade Católica de Pelotas receber a carta aos editores intitulada "Depressão durante a

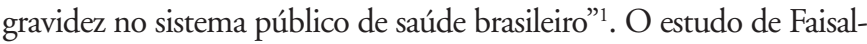

Cury é um ótimo trabalho com a mesma população-alvo e foi citado por nosso grupo no artigo intitulado "Transtornos mentais comuns (TMC), autoestima e fatores associados em gestantes'3 ${ }^{3}$ já aprovado no periódico Cadernos de Saúde Pública e que aguarda publicação. Entretanto, não foi incluído em nossa revisão, nem o consideramos um estudo antecedente ao nosso presente artigo, uma vez que seu estudo apresenta uma diferente medida de avaliação e desfecho. $\mathrm{O}$ estudo de Faisal-Cury utilizou uma entrevista clínica que tem por objetivo avaliar sintomas psiquiátricos em seu conjunto (transtornos mentais), que incluem inquietação, irritabilidade, ansiedade, preocupação somática, problemas do sono e da concentração, fadiga, humor depressivo, comportamento compulsivo e obsessivo, hipocondria, fobias e pânico, agrupados em TMC. A investigação verificou os fatores associados a este conjunto, enquanto nosso estudo verificou fatores associados especificamente o quadro de depressão gestacional, por meio da Edinburgh Postnatal Depression Scale (EPDS), instrumento com validação para esta população. Mesmo com tais diferenças metodológicas, os manuscritos reforçam a necessidade de que se atente para a necessidade de avaliação e tratamento de transtornos mentais na gestação e puerpério.

Ricardo Azevedo da Silva, Karen Jansen, Luciano Dias Mattos de Souza, Inácia Gomes da Silva Moraes, Elaine Tomasi, Giovanna Del Grande da Silva, Michelle Souza Dias, Ricardo Tavares Pinheiro Universidade Católica de Pelotas, Pelotas, RS, Brasil

Financiamento e conflito de interesses

\begin{tabular}{|c|c|c|c|c|c|c|c|}
\hline $\begin{array}{l}\text { Membro do grupo } \\
\text { de autores }\end{array}$ & $\begin{array}{l}\text { Local de } \\
\text { trabalho }\end{array}$ & $\begin{array}{l}\text { Verba de } \\
\text { pesquisa }\end{array}$ & $\begin{array}{c}\text { Outro apoio à } \\
\text { pesquisa ou educação } \\
\text { médica continuada }\end{array}$ & $\begin{array}{l}\text { Honorários } \\
\text { de } \\
\text { palestrantes }\end{array}$ & $\begin{array}{l}\text { Participação } \\
\text { acionária }\end{array}$ & $\begin{array}{l}\text { Consultorl } \\
\text { conselho } \\
\text { consultivo }\end{array}$ & Outro $^{3}$ \\
\hline $\begin{array}{l}\text { Ricardo Azevedo da } \\
\text { Silva }\end{array}$ & UCPel & - & - & - & - & - & - \\
\hline Karen Jansen & UCPel & - & - & - & - & - & - \\
\hline $\begin{array}{l}\text { Luciano Dias Mattos } \\
\text { de Souza }\end{array}$ & UCPel & - & - & - & - & - & - \\
\hline $\begin{array}{l}\text { Inácia Gomes da } \\
\text { Silva Moraes }\end{array}$ & UCPel & - & - & - & - & - & - \\
\hline Elaine Tomasi & UCPel & - & - & - & - & - & - \\
\hline $\begin{array}{l}\text { Giovanna Del Grande } \\
\text { da Silva }\end{array}$ & UCPel & - & - & - & - & - & - \\
\hline Michelle Souza Dias & UCPel & - & - & - & - & - & - \\
\hline $\begin{array}{l}\text { Ricardo Tavares } \\
\text { Pinheiro }\end{array}$ & UCPel & - & - & - & - & - & - \\
\hline
\end{tabular}

* Modesto

** Significativa

*** Significativa. Montantes fornecidos à instituição do autor ou a colega onde o autor tem participação, não diretamente ao autor. Nota: UCPel = Universidade Católica de Pelotas.

Mais informações, consultar as Instruções aos Autores.

Referências

1. Silva RA, Jansen K, Souza LDM, Moraes IGS, Tomasi E, Silva GDG, Dias MS, Pinheiro RT. Depression during pregnancy in the Brazilian public health care system. Rev Bras Psiquiatr. 2010;32(2):139-44.

2. Faisal-Cury A, Menezes P, Araya R, Zugaib M. Common mental disorders during pregnancy: prevalence and associated factors among low- income women in São Paulo, Brazil. Arch Womens Ment Health. 2009; $12: 335-43$.

3. Silva RA, Ores LC, Mondin TC, Rizzo RN, Moraes IGS, Jansen K, Pinheiro RT. Transtornos mentais comuns e auto-estima na gestação: prevalência e fatores associados. Cad Saude Publica. In press, 2010. 